\title{
Correlation between Interleukin-6 Levels and Total PANSS Scores in Batak People with Schizophrenia
}

\author{
Suniaty Dapotria Lumbantoruan, Elmeida Effendy*, Mustafa M. Amin \\ Department of Psychiatry, Faculty of Medicine, Universitas Sumatera Utara, Medan, Indonesia
}

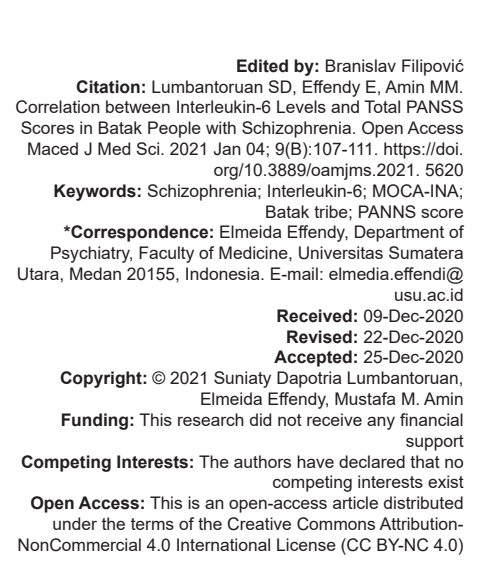

Introduction

Schizophrenia is a psychotic disorder that often occurs with a risk of about $1 \%$. The most common early onset of the disease is between 15 and 30 years old. This disorder is a chronic disease that disrupts patients and their families to have a major social and economic impact. Some studies found that men experienced more negative symptoms than women. Female had better social functions than men before the onset of the disease. In general, female schizophrenic patients have better outcomes than men [1].

Researchers have shown that environmental contributions can lead to the involvement of brain and chemical circuits, especially early in life. It can result in irregular stages of the developmental process in the central nervous system (CNS) and ultimately lead to schizophrenia. Furthermore, researchers have also found that cytokines play an important role in altering the course of maturation in the normal brain. The cytokine hypothesis postulates that exposure to proinflammatory cytokines at birth is caused by maternal immune activation, which can cause abnormalities in fetal brain development [2]. Moreover, pro-inflammatory cytokines, such as Interleukin (IL)-6, IL-12, tumor necrosis factor- $\alpha, \mathrm{IL}-1 \beta$, and interferon (IFN)- $\gamma$, were reported to improve in schizophrenic patients [1]. The exact etiology of psychosis is unknown. Disturbances in the body immune mechanisms are thought to play an important role in schizophrenic psychosis. Although impaired immune mechanisms are mainly found in peripheral blood and cerebrospinal fluid, these mechanisms are also reported to stem from inflammatory processes in the CNS [3].

Furthermore, peripheral inflammation involves increased IL-6 release, which is associated with two other characteristics of negative symptoms, namely inattention and psychomotor retardation [4], [5]. The increased pro-inflammatory signaling may also play a role in the appearance of positive symptoms. The particular interest in this context is the stimulating effects of pro-inflammatory cytokines on dopamine and the synthesis and release of noradrenaline [4]. During acute exacerbations, IL-1 $1 \beta$, IL- 6 , and IFN- $\beta$ increased in patients with schizophrenia but not normalized by antipsychotic treatment [6].

A study conducted by Frydecka and Misiak (2015) in Poland found that IL-6 in schizophrenic patients $(n=151)$ increased significantly compared to the control 
group $(\mathrm{n}=194)$. The mean of the schizophrenia group was $1.4 \pm 2.23$, and the mean of the control group was $1.07 \pm 0.77$ with a $p=0.049$. Furthermore, no correlation was found between IL-6 with positive symptoms $(r=-0.05 ; p=0.66)$, negative symptoms $(r=0.15$; $p=0.23)$, general symptoms $(r=-0.04 ; p=0.73)$, and depression item scores $(r=0.19 ; p=0.10)$ [7]. The study results conducted also reported that each ethnicity had different levels of cytokines [7].

Moreover, another study by Luo et al. (2019) in China found that IL- 6 had a positive correlation with negative symptoms $(r=0.275 ; p<0.01)$ when the patient was admitted. However, at the time of discharge, there was a positive correlation with positive symptoms $(r=0.473 ; p<0.01)$, negative symptoms $(r=0.435 ; p$ $<0.01)$, and the total scores $(r=0.331$; $p<0.01)$ [8]. In contrast, Zang et al. (2004) who conducted a study in Beijing (China) reported that before the treatment, there was no correlation between IL- 6 and the total PANSS score with a total score $(r=-0.11$; $p<0.11)$, positive symptoms $(r=-0.01 ; p<0.93)$, and negative symptoms $(r=0.07 ; p<0.56)$ [9].

Therefore, the researchers were interested in assessing the correlation between IL-6 and the total PANSS score using the Positive and Negative Syndrome Scale in people with schizophrenia. Based on the literature study, no previous study related to this has been conducted in Indonesia, especially in North Sumatra. Thus, the present study would be the first study, so it required further research.

\section{Methods}

The design of this research was numericnumeric correlation analytic study. The crosssectional study approach assessed the correlation between IL-6 levels and total PANSS score in people with schizophrenia from the Batak tribe who were hospitalized in Prof. Dr. M. Ildrem Mental Hospital, Sumatra Province that met the inclusion and exclusion criteria. The sampling method was using non-probability sampling with consecutive sampling [10]. The research was conducted from January to February 2020.

The inclusion criteria were people with schizophrenia from the Batak tribe who met the PPDGJI-III criteria, in the acute phase of treatment $\leq 4$ weeks, aged 15-45 years, duration of illness $\leq 5$ years, ideal body weight $(\mathrm{BMI}=18.5-24.99)$, willing to be a respondent and interviewed, and under the antipsychotic risperidone consumption. In contrast, the exclusion criteria were previous history of general medical diseases and/or other comorbidities, neurological and autoimmune diseases, and history of substance use (except caffeine, moderate, and heavy smoking).

\section{Measurement}

IL-6 levels were obtained from the blood serum test, which was enzyme-linked immunosorbent assay (ELISA) kit, namely "Human Interleukin-6 ELISA Kit, Size 96 Wells Brands Bioassay Technology Laboratory." The blood was then taken to the laboratory for examination of serum IL-6. This study has received approval from the Research Ethics Committee at the Faculty of Medicine, Universitas Sumatera Utara, Indonesia.

\section{Statistical analysis}

The analysis test was carried out on the two variables, namely, IL-6 levels and the total PANSS score. Before the correlation test, the data normality test was performed using the Shapiro-Wilk test because the sample size was $<50$ [11]. If the data are normally distributed, it is followed by the Pearson correlation test. On the contrary, if the data are not normally distributed, the data will be normalized first before the Spearman correlation test can be carried out. The correlation value was determined by the r-value (strength and direction of correlation) and p-value (limit of conclusion), where $p=0.05$. Data processing and data analysis were performed using the Statistical Package for the Social Sciences software.

\section{Results}

The results of this study are summarized in Table 1.

Table 1: Distribution of research subjects based on demographic characteristics

\begin{tabular}{|c|c|c|c|}
\hline Variables & $\mathrm{n}$ & $\%$ & $\mathrm{p}$ \\
\hline \multicolumn{4}{|l|}{ Age (years) } \\
\hline Mean (min-max) & $15-45$ & $30.87(27-40)$ & $0.001^{*}$ \\
\hline \multicolumn{4}{|l|}{ Gender } \\
\hline Male & 26 & $(55.3)$ & \\
\hline Female & 21 & $(44.7)$ & \\
\hline \multicolumn{4}{|l|}{ Marital status } \\
\hline Married & 16 & $(34.0)$ & \\
\hline Not married & 31 & $(66.0)$ & \\
\hline \multicolumn{4}{|l|}{ Employment status } \\
\hline Employed & 18 & $(38.3)$ & \\
\hline Unemployed & 29 & $(61.7)$ & \\
\hline \multicolumn{4}{|l|}{ Education } \\
\hline Junior high school & 9 & (19.1) & \\
\hline Senior high school & 34 & (72.3) & \\
\hline \multirow{2}{*}{\multicolumn{4}{|c|}{ Duration of illness }} \\
\hline & & & \\
\hline Mean (min-max) & $4.00(2-5)$ & & $0.001^{*}$ \\
\hline \multicolumn{4}{|l|}{ Body mass index } \\
\hline Mean (min-max) & $21.62(17.89-26.32)$ & & $0.08^{\star}$ \\
\hline \multicolumn{4}{|l|}{ Levels of IL-6 } \\
\hline \multicolumn{4}{|l|}{ Mean $\pm s . b$} \\
\hline Male & $6.93 \pm 2.23$ & & $0.79^{*}$ \\
\hline Female & $6.25 \pm 2.17$ & & $0.22^{*}$ \\
\hline \multicolumn{4}{|l|}{ PANSS score } \\
\hline \multicolumn{4}{|l|}{ Mean $\pm s . b$} \\
\hline Positive symptom & $29.98 \pm 4.93$ & & $0.88^{*}$ \\
\hline Negative symptom & $24.28 \pm 4.24$ & & $0.12^{*}$ \\
\hline General psychopathology & $43.13 \pm 5.42$ & & $0.03^{*}$ \\
\hline Total PANSS score & $97.38 \pm 9.29$ & & $0.27^{*}$ \\
\hline
\end{tabular}

The characteristics of research subjects can be seen in Table 1. In terms of age, the mean age 
(minimum-maximum) in people with schizophrenia was 30.87 (27-40). After the normality test was performed, the data obtained a value of 0.001 ( $p<0.05)$, which means that the data were not normally distributed.

In this study, there were $55.3 \%$ and $44.7 \%$ of male and female subjects. In terms of marital status, $34.0 \%$ was married and the rest unmarried. Based on the employment status, $38.3 \%$ was employed and $61.7 \%$ was unemployed. In the education level, $19.1 \%$, $72.3 \%$, and $8.5 \%$ had junior high school, senior high school, and a university-level, respectively.

Moreover, the mean (minimum-maximum) of the duration of illness for people with schizophrenia was 4.00 (2-5). The normality test of the data depicted that the data were not normally distributed with a value of 0.001 ( $p<0.05)$. The value of the body mass index of research subjects was 21.62 (17.89-26.32), while the normality test obtained a value of 0.08 ( $p>0.05)$ which means that the data were normally distributed.

The mean of IL-6 levels in men with schizophrenia was $6.93 \mathrm{ng} / \mathrm{ml}$ with a standard deviation of 2.23 . The normality test of the data showed a value of $0.79(p>0.05)$. On the other hand, the normality test for IL-6 levels in women with schizophrenia which had a mean of $6.25 \mathrm{ng} / \mathrm{ml}$ and a standard deviation of 2.17 obtained a value of $0.22(p>0.05)$.

The PANSS score for positive symptoms in people with schizophrenia had a mean of 29.98 and a standard deviation of 4.93 with a p-value of 0.88 $(p>0.05)$. Similarly, negative symptoms obtained a mean of 24.28 and a standard deviation of 4.24 with a $p$-value of $0.12(p>0.05)$. In contrast, the normality test of general psychopathology which had a mean of 43.13 and a standard deviation of 5.42 depicted that the data were not normally distributed with a $p$-value of 0.03 ( $p<0.05$ ). Furthermore, the normality test of the total PANSS score with a mean of 97.38 and a standard deviation of 9.29 obtained a $p$-value of $0.27(p>0.05)$.

The results of the Pearson correlation test obtained a $\mathrm{p}<0.05$, which means that there was a correlation between IL-6 levels and total PANSS score. The strength of the relationship which was 0.657 showed a positive correlation, indicating that the higher the level of IL-6, the higher the PANSS total score was with a strong correlation strength $(0.6-<0.8)$. The correlation between IL-6 levels and the total PANSS scores in people with schizophrenia from the Batak tribe is summarized in Table 2.

Table 2: The correlation between IL- 6 levels and the total PANSS scores in people with schizophrenia from the Batak tribe

\begin{tabular}{ll}
\hline Variable & IL-6 Levels \\
\hline Total PANSS score & $\mathrm{r}=0.657$ \\
& $\mathrm{p}=0.001$ \\
& $\mathrm{n}=47$
\end{tabular}

In addition, the Pearson correlation test found that there was a positive correlation between IL-6 levels and positive symptom scores with a $p<0.05$. Table 3 depicts the correlation between IL- 6 levels and positive symptom scores.

Table 3: The correlation between IL-6 levels and positive symptom scores in people with schizophrenia from the Batak tribe

\begin{tabular}{ll}
\hline Variable & IL-6 Levels \\
\hline Positive symptom scores & $\mathrm{r}=0.696$ \\
& $\mathrm{p}=0.001$ \\
$\mathrm{n}=47$
\end{tabular}

Table 4 shows that there was a correlation between IL-6 levels and negative symptom scores with a $p<0.05$. The strength of the relationship of 0.532 indicated a positive correlation, which means that the higher the level of IL-6, the higher the negative symptom score with a moderate correlation strength $(0.4-<0.6)$.

Table 4: The correlation between IL-6 levels and negative symptom scores in people with schizophrenia from the Batak tribe

\begin{tabular}{ll}
\hline Variable & IL-6 Levels \\
\hline Negative symptom scores & $\mathrm{r}=0.532$ \\
& $\mathrm{p}=0.001$ \\
& $\mathrm{n}=47$ \\
\hline IL: Interleukin. &
\end{tabular}

Table 5 depicts the correlation between general psychopathological scores and IL-6 levels. The results of the Pearson correlation test found that there was no correlation between IL-6 levels and general psychopathological scores $(r=0.076)$ with a $p>0.05$.

Table 5: The correlation between IL-6 levels and general psychopathology scores in people with schizophrenia from the Batak tribe

\begin{tabular}{ll}
\hline Variable & IL-6 Levels \\
\hline General psychopathology scores & $\mathrm{r}=0.076$ \\
& $\mathrm{p}=0.611$ \\
& $\mathrm{n}=47$ \\
\hline IL: Interleukin. &
\end{tabular}

\section{Discussion}

In this study, the correlation between IL-6 levels and the total PANSS scores was analyzed in 47 people with schizophrenia from the Batak tribe who were hospitalized at Prof. Dr. M. Ildrem Mental Hospital Medan and have met the inclusion and exclusion criteria.

Based on demographic characteristics shown in Table 4.1, the mean age of subjects (min-max) was 30.87 (27-40). The study results conducted by Frydecka and Misiak in 2015 found that the age of subjects was 38-46 with the inclusion criteria for the age was 38-46 years. This is because the concentration of cytokines such as IL-6 would increase cytokine levels in older age, and this relationship was considered a linear process, and each ethnic group has different levels of cytokines [7].

There were 26 male subjects $(55.3 \%)$ and 21 female subjects $(44.7 \%)$ participated in the study. 
However, there was no difference found in the IL-6 levels between men and women. Similarly, a study by Frydecka and Misiak in 2015 also found no difference in the IL- 6 between 82 female subjects and 69 male subjects recruited as her subjects [7].

Based on the duration of illness, the mean (minimum-maximum) in people with schizophrenia was 4.00 (2-5). However, only people who had schizophrenia for $\leq 5$ years were recruited as research subjects in the study. A study by Kubistova et al. in 2012 found higher IL-6 in patients with a duration of illness $>5$ years [12]. Furthermore, research by Mohsen in 2017 reported higher levels of IL- 6 in subjects with an average length of illness of 9 years with a value of 35.3 \pm 10.1 [13].

In terms of body mass index, the mean (minimum-maximum) was 21.62 (17.89-26.32). According to Mohsen's study in 2017, IL-6 increased in obesity [13]. The mean of IL-6 levels in men with schizophrenia were $6.93 \mathrm{ng} / \mathrm{ml}$, while the mean of IL-6 levels in women with schizophrenia were $6.25 \mathrm{ng} / \mathrm{ml}$. Thus, there was no difference in the levels of IL- 6 based on gender.

The acute phase of treatment was $\leq 4$ weeks in people with schizophrenia. Mohsen in 2017 found that IL-6 increased in the acute phase of treatment $\leq 4$ weeks, but after 8 weeks of treatment, there was a decrease in IL-6 [13]. In this study, the subjects were people with schizophrenia from the Batak tribe because Frydecka's research in 2015 found that levels of IL-6 differ based on ethnicity [7].

The result of this study is consistent with the study conducted by Frydecka and Misiak in Poland in 2015 [7], which found a positive correlation between levels of IL-6 and negative symptom scores $(r=0.15$; $\mathrm{p}=0.23$ ). Furthermore, a study by Luo et al. in China in 2019 reported that IL-6 correlated positively with negative symptom scores $(r=0.275 ; p<0.01)$ [8]. In addition, this study found that there was no correlation of IL-6 with general psychopathology symptom due to the inclusion subjects used being patients with acute schizophrenia under medication for 4 weeks and risperidone antipsychotic consumption. IL-6 and the PANSS score decreased during therapy. The result was the same as Kubistova study [12]. They concluded that IL-6 increased in plasma of people with schizophrenia, but it would decrease under medication [12].

\section{Conclusions}

1. There was a correlation between IL-6 levels and the total PANSS scores in people with schizophrenia from the Batak tribe $(p=0.001$; $r=0.657$ ).
2.

There was a correlation between IL-6 levels and positive symptom scores in Batak people with schizophrenia $(p=0.001 ; r=0.696)$.

3. There was a correlation between IL-6 levels and negative symptom scores in people with schizophrenia from the Batak tribe $(p=0.001$; $r=0.532$ ).

4. There was no correlation between IL-6 levels and general psychopathological scores in Batak people with schizophrenia.

\section{References}

1. Miller BJ, Gassama B, Sebastian D, Buckey P, Mellor A. Metaanalysis of lymphocytes in schizophrenia. Clinical status and antipsychotic effects. Biol Psychiatry. 2013;73(10):993-9. https://doi.org/10.1016/j.biopsych.2012.09.007

PMid:23062357

2. Howard J. The cytokine hypothesis: A neurodevelopmental explanation for the emergence of schizophrenia later in life. Adv Biosci Biotechnol. 2013;4:81-8.

3. Doorduin J. de Vries EF, Willemsen AT, de Groot JC, Dierckx RA, Klein HC. Neuroinflammation in schizophrenia-related psychosis: A PET study. J Nucl Med. 2016;50(11):1801-7. https://doi.org/10.2967/jnumed.109.066647

PMid:19837763

4. Meyer U. The psychotic face of the immune system: Inflammation and schizophrenia. In: The Wiley-Blackwell Handbook of Psychoneuroimmunology. West Sussex: John Wiley \& Sons; 2014. p. 411-24. https://doi.org/10.1002/9781118314814.ch21

5. Meyer U, Schwarz M, Muller N. Inflammatory processes in schizophrenia: A promising neuroimmunological target for the treatment of negative/cognitive symptoms and beyond. Pharmacol Ther. 2011;132(1):96-110. https://doi.org/10.1016/j. pharmthera.2011.06.003

PMid:21704074

6. Kneeland RE, Fatemia SH. Viral infection, inflammation and schizophrenia. Prog Neuropsychopharmacol Biol Psychiatry. 2013;42:35-48.

PMid:22349576

7. Frydecka D, Misiak BM. Interleukin-6: The missing element of the neurocognitive deterioration in schizophrenia? The focus on genetic underpinnings, cognitive impairment and clinical manifestation. Eur Arch Psychiatry Clin Neurosci. 2015;265(6):449-59. https://doi.org/10.1007/ s00406-014-0533-5

PMid:25214388

8. Luo Y, He H, Zhang J, Fan N. Changes in serum TNF- $\alpha$, IL-18, and IL-6 concentrations in patients with chronic schizophrenia at admission and at discharge. Compr Psychiatry. 2019;90:82-7. https://doi.org/10.1016/j.comppsych.2019.01.003 PMid:30782515

9. Zhang XY, Zhou DF, Cao LY, Zhang PY, Wu GY, Shen YC. Changes in serum interleukin-2, -6 and -8 levels before and during treatment with risperidone and haloperidol: Relationship to outcome in schizophrenia. J Clin Psychiatry. 2004;65(7):940-7. https://doi.org/10.4088/jcp.v65n0710 PMid:15291683

10. Sastroasmoro S, Ismail S. Dasar dasar metedologi penelitian klinis. In: Edisi Ketiga. Jakarta: Sagung Seto; 2008. 
11. Dahlan MS. Statistik untuk kedokteran dan kesehatan: Deskriptif, bivariat dan multivariat, dilengkapi dengan menggunakan SPSS. In: Edisi Kelima. Jakarta: Salemba Medika; 2014.

12. Kubistova A, Horacek J, Novak T. Increased interleukin-6 and tumor necrosis factor alpha in first episode schizophrenia patients versus healthy controls. Psychiatr Danub. 2012;23 Suppl 1:S153-6.
PMid:22945211

13. Mohsen MY, Sabry NA, Zyada F, Samie MA, Baz HN Relationship of serum interleukin- 6 and cognitive functions in patients with schizophrenia, a case-control study. Middle East Curr Psychiatry. 2017;24(4):181-6. https://doi.org/10.1097/01. xme.0000522264.90841 